\title{
Anthony M. Wachinski: Environmental Ion Exchange, Principles and Design. 2nd Edn
}

\author{
Alan Dyer ${ }^{1}$
}

(C) Springer-Verlag Berlin Heidelberg 2016

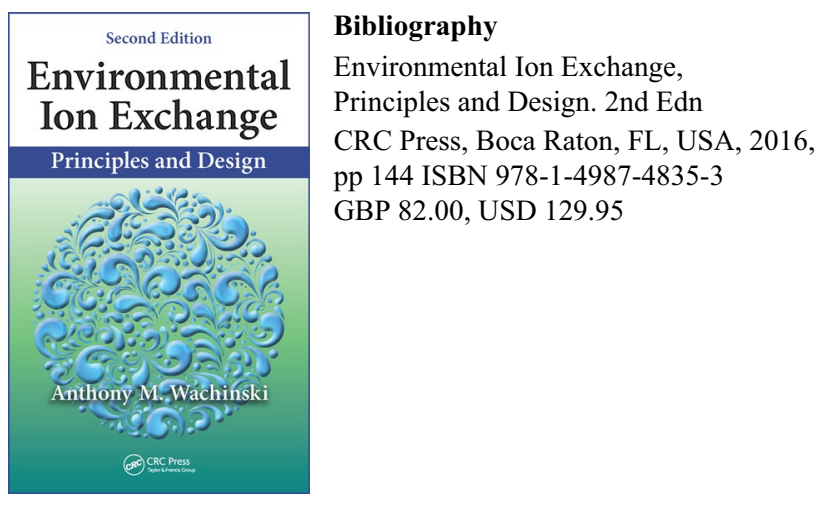

This publication is intended for water engineers involved in processes designed to produce "safe" municipal water, pure demineralised water, and other treatments of wastewater.

The content concentrates on the use of organic ionexchange resins with a comprehensive definition of terms relevant to the operation of ion-exchange columns for various tasks.

Details of available resins designed as strong or weak base exchangers-both cation and anion-are given and specific problems are provided which cover common industrial applications, including worked examples. There are 20 pages of useful appendices supplying tables, conversion factors, and other essential resin details.

The title of the book may mislead some readers as they might expect a section on the importance of toxic ions and their interaction with clays in soils. The author mentions that a Google search records over 9.5 million hits for ion exchange. This coverage will include the large literature devoted to zeolites and their ability to show high degrees of selectivity for toxic metal ions. Unfortunately, this book wrongly defines these minerals as "processed natural clays" or "silica gels", lists several which are not spelt correctly, and omits to mention the importance of clinoptilolite (used to scavenge $\mathrm{Cs}$ and $\mathrm{Sr}$ nuclides in nuclear clean-up, such as in Three Mile Island, Chernobyl, and Fukushima). These deficiencies could be solved by additional references, as could the more accurate description of ion exchange as rate controlled by diffusion which should be prominent in the "Basics" paragraph in Chapter 3.

Readers should note the use of $\mathrm{K}$ rather than $\mathrm{k}$ for kilo and $\mathrm{G}$ the gravitational constant for $\mathrm{g}$ (grams).
Alan Dyer

chromatographia@springer.com

1 Darwen, Lancashire, UK 